
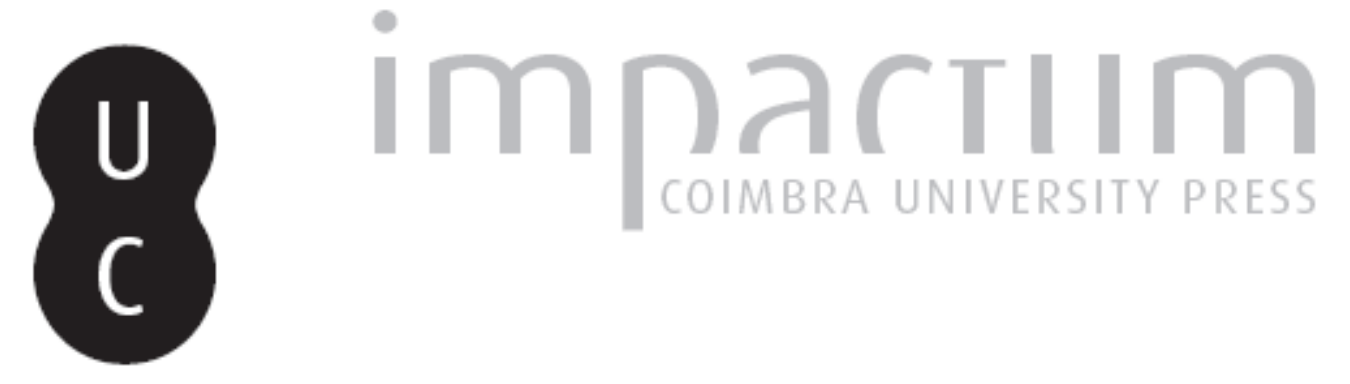

\title{
Heranças bucólicas na Arcádia Lusitana
}

Autor(es): $\quad$ Marnoto, Rita

Publicado por: Imprensa da Universidade de Coimbra

URL persistente: URI:http://hdl.handle.net/10316.2/42613

DOI: DOI:https://doi.org/10.14195/0870-8584_3_10

Accessed : $\quad$ 26-Apr-2023 15:42:29

A navegação consulta e descarregamento dos títulos inseridos nas Bibliotecas Digitais UC Digitalis, UC Pombalina e UC Impactum, pressupõem a aceitação plena e sem reservas dos Termos e Condições de Uso destas Bibliotecas Digitais, disponíveis em https://digitalis.uc.pt/pt-pt/termos.

Conforme exposto nos referidos Termos e Condições de Uso, o descarregamento de títulos de acesso restrito requer uma licença válida de autorização devendo o utilizador aceder ao(s) documento(s) a partir de um endereço de IP da instituição detentora da supramencionada licença.

Ao utilizador é apenas permitido o descarregamento para uso pessoal, pelo que o emprego do(s) título(s) descarregado(s) para outro fim, designadamente comercial, carece de autorização do respetivo autor ou editor da obra.

Na medida em que todas as obras da UC Digitalis se encontram protegidas pelo Código do Direito de Autor e Direitos Conexos e demais legislação aplicável, toda a cópia, parcial ou total, deste documento, nos casos em que é legalmente admitida, deverá conter ou fazer-se acompanhar por este aviso.

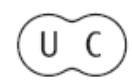




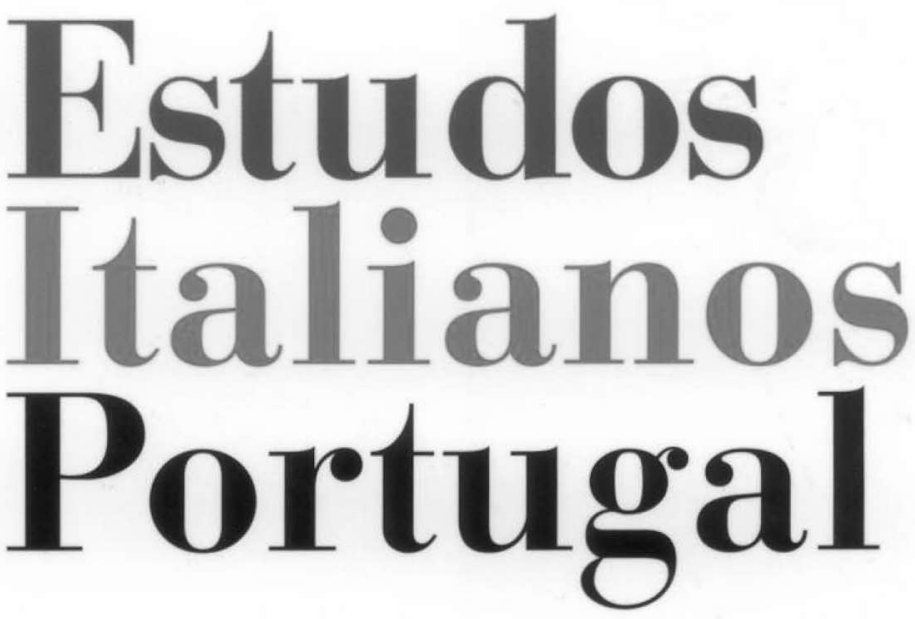

Instituto

Italiano

de Cultura

de Lisboa

Nova Série

$\mathrm{N}^{\circ} 3$

2008 


\title{
HERANÇAS BUCÓLICAS \\ NA ARCÁDIA LUSITANA
}

\author{
Rita Marnoto*
}

O вucolismo impregna a actividade da Arcádia Lusitana de um modo penetrante, fundacional, que se estende pelos mais diversos âmbitos. Foi em 1757 que se realizou a primeira sessão da célebre agremiação literária, criada no ano anterior, que teve por sócios António Dinis da Cruz e Silva (que usou o pseudónimo arcádico de Elpino Nonacriense), Manuel Nicolau Esteves Negrão (Almeno Sincero), Teotónio Gomes de Carvalho (Tirse Minteo), Pedro António Correia Garção (Coridão Erimateu), Domingos dos Reis Quita (Alcino Micénio) ou Manuel de Figueiredo (Lícidas Cíntio), entre outros ${ }^{1}$. O horizonte do mundo dos pastores fica bem patente não só na sua produção literária e nas reflexões de

* Professora de Literatura Italiana, Literatura Comparada e Tradução, Directora do Instituto de Estudos Italianos da Faculdade de Letras da Universidade de Coimbra. Tem-se vindo a dedicar ao estudo de diversas épocas e de vários autores. Este texto retoma intervenções feitas em 2006, numa mesa-redonda organizada pelo Gabinete de Estudos Olissiponenses e no Colóquio Internacional Heranças Bucólicas. Paisagens, Paraísos, Peregrinações, do Centro de Estudos Linguísticos e Literários.

${ }^{1}$ São os primeiros nomes da lista publicada por Francisco Manuel Trigoso d'Aragão Morato na "Memória sobre o estabelecimento da Arcádia de Lisboa e sobre a sua influência na restauração da nossa literatura", in História e Memórias da Academia Real das Ciências de Lisboa, t. 6, parte 1, 1819, p. 81. Este trabalho de Aragão Morato continua a ser a síntese histórica de referência acerca da actividade da Arcádia Lusitana. 
ordem teórica que acerca dele foram elaboradas por vários dos seus membros, como também numa atitude comportamental cujo espectro vai do plano poético ao do desempenho socializante.

A renovação dos rumos do pastoralismo é acompanhada por um cuidadoso trabalho de leitura e de aprofundamento de fontes. A atenção conferida ao mais antigo poeta bucólico que se conhece, Teócrito, anda associada à leitura de Iacopo Sannazaro e da sua Arcadia, em cujas páginas são imitados gregos e romanos, bem como todos os grandes autores neolatinos e em língua vulgar que vão até ao final do século XV, com relevo para os bucolistas. Foi, para os séculos seguintes, um enorme ecrã dotado de incomensurável capacidade projectiva sobre as várias literaturas europeias. A largueza de interesses dos membros da Arcádia Lusitana é também ilustrada pelo campo da tradução. Se Francisco José Freire traduziu Sannazaro ${ }^{2}$, num momento mais adiantado do século um prestigiado membro da Academia das Ciências, Joaquim de Foios, editará Teócrito em versão portuguesa ${ }^{3}$.

A produção bucólica dos Árcades, considerada no contexto da literatura setecentista, assinala um foco de renovação e um ponto de viragem ${ }^{4}$. Nas obras de Cruz e Silva, andam 25 composições genericamente designadas como

2 Em manuscrito actualmente depositado na Biblioteca e Arquivo Distrital de Évora. Vd. Giuseppe Carlo Rossi, "Il Sannazaro in Portogallo", in Romana, 7, 3, 1943, pp. 154-163; e, mais recentemente, Zulmira Santos, Literatura e espiritualidade na obra de Teodoro de Almeida (1722-1804), Lisboa, FCG, FCT, 2007, passim.

3 Nas Memórias da Literatura Portuguesa $(1,1792)$. Vd. Nuno Simões Rodrigues, Traduções portuguesas de Teócrito, prefácio de Victor Jabouille, organização, introdução e notas de N. S. R., Lisboa, Universitária, 2000.

${ }^{4}$ Retomo as conclusões dos trabalhos que dediquei à contaminatio e à questão da natureza, "Teoria dos géneros e prática literária na Arcádia Lusitana. O processo de contaminatio", in José A. Sánchez Marín, M. Nieves Muñoz Martín (eds.), Retórica, poética y géneros literarios, Granada, Universidad de Granada, 2004, pp. 599 -626; e à relação entre Baco e a tragédia, "Os Gigantes da Montanha de Luigi Pirandello - 'nada que ver com Dioniso' ", in Humanitas, 50, 1998, pp. 1001-1018. 
idílios, cujos temas são muito variados ${ }^{5}$. O poeta cria efeitos dramáticos, espectaculares, e através de um elaborado processo de contaminatio traz Baco para uma Arcádia agitada pelo deus da tragédia e animada pelos ecos da poesia ditirâmbica. $\mathrm{Na}$ verdade, a reinvenção do ditirambo anda indissoluvelmente associada ao deus da vinha, logo a partir daquele momento em que Francesco Redi lançou o seu marco fundador, em 1666, com o famoso Baco in Toscana. O 19. idílio de Cruz e Silva, Epileneu, põe pela primeira vez em cena, na literatura portuguesa, dois vindimadores. Aliás, a atracção pelos grandes quadros naturais será uma constante do percurso intelectual do poeta que, anos volvidos, se deixará fascinar pelo exotismo brasileiro nas suas doze Metamorfoses ${ }^{6}$. Por sua vez, Domingos dos Reis Quita escreveu, além de idílios, 13 éclogas dialogadas, nas quais trata assuntos de devoção, amorosos e de circunstância ${ }^{7}$. Foi autor do primeiro drama pastoril da literatura portuguesa, Lícore. Esta obra é um lídimo representante daquele filão rasgado por Torquato Tasso com o Aminta. Encenado para a corte de Ferrara em 1573, tendo por cenário natural os jardins da ilha de Belvedere, situada no Pó, inaugura uma tipologia mista depois imitada em muitas literaturas.

No domínio da conceptualização teórica elaborada em torno do bucolismo, destacam-se as dissertações sobre o estilo das éclogas lidas por Cruz e Silva à Arcádia Lusitana nas sessões realizadas em Setembro e em Outubro de 1757. A separação de campos entre a écloga e o rústico carrega em si objectivos polémicos, na diatribe com Pina e Melo. Toda-

5 Vd., mais recentemente, as Obras de António Dinis da Cruz e Silva, introdução, fixação de texto e notas de Maria Luísa Malaquias Urbano, Lisboa, Colibri, 2000-2003, 3 vol.

${ }^{6}$ No Brasil, empreendeu também estudos de mineralogia, cujos tomos andam perdidos.

$7 \mathrm{Vd}$., mais recentemente, as Obras completas de Domingos dos Reis Quita, edição de Ana Cristina Fontes, Porto, Campo das Letras, 1999, 2 vol. 
via, nela fica contido, da mesma feita, um esforço empenhado na legitimação e no enaltecimento desse género literário. Nas suas reflexões, a familiaridade com os grandes cultores do bucolismo (Teócrito, Virgílio, Sannazaro, Garcilaso, Henrique Caiado, Camões, Tasso, etc.) articula-se com um conhecimento bastante próximo da teorização epocal (Muratori, Boileau, Fontenelle, Pope, etc.).

Mas as grandes questões de poética e de teoria literária que os Árcades se colocam muito têm a ver com o bucolismo, em particular pelo que diz respeito aos conceitos de natureza e de utile. A grande utilidade das letras reside na possibilidade que lhes é própria de restituírem o homem à sua autêntica natureza, na sua simplicidade e com uma atitude de despojamento que são denominador comum entre a estética neoclássica e o universo poético dos pastores ${ }^{8} . \mathrm{Na}$ problemática acerca da imitação, a natureza não é apenas entendida como um referente abstracto: é modalidade e objectivo da pesquisa que visa dilucidar a ligação entre literatura, homem, enquadramento natural e sociedade, como se todos eles fossem planificações instauradoras de uma mesma figura. Nesse contexto, as letras assumem uma função primária, que as converte em meio de fundamental utilidade no apuramento dos valores simples que restituem ao homem a sua verdadeira dimensão, que é dizer, a sua verdadeira natureza. Nas obras de Quita, anda um texto, que lhe foi dirigido por um amigo anónimo, intitulado Carta sobre a utilidade da poesia, e Correia Garção, ao iniciar a pri-

8 As implicações cívicas do bucolismo serão reiteradamente recordadas pelo arcadismo português. São tema central da "Memória sobre a poesia bucólica dos poetas portugueses”, publicada, na última década do século XVIII, por Joaquim de Foios, membro da Arcádia Lusitana e da Academia Real das Ciências, nas Memórias da Literatura Portuguesa $(1,1792)$ e depois na História e Memórias da Academia Real das Ciências $(1,1797)$. Daí decorrerá uma controvérsia analisada por Ofélia Paiva Monteiro em D. Frei Alexandre da Sagrada Família. A sua espiritualidade e a sua época, Coimbra, Acta Universitatis Conimbrigensis, 1974, pp. 75 ss. 
meira dissertação sobre a tragédia, dirige-se aos seus confrades com entusiasmo, sobrevalorizando esse objectivo relativamente a outros fins da academia:

De que arte ou de que ciência poderei combinar uma regra de que vós, melhor do que eu, não conheçais profundamente toda a sua extensão? Assim é, senhores: porém vós, quando me chamastes para membro desta sociedade, concebestes outra ideia mais ilustre. Quisestes ser úteis à Pátria: e um projecto tão generoso não se pode praticar sem, com efeito, ensinardes os vossos compatriotas. ${ }^{9}$

Muito para além de qualquer circunstancialismo, o utile, nas suas relações com o movere e com o delectare, é um tema e uma preocupação que percorre, transversalmente, a produção teórica e a prática literária dos Árcades nos seus objectivos de instrução, situando-se assim numa linha de continuidade em relação ao programa traçado por Luís António Verney na obra que sintomaticamente intitulou, Verdadeiro método de estudar para ser útil à República e à Igreja proporcionado ao estilo e necessidade de Portugal exposto em várias cartas.

A reflexão em torno da imitação da natureza e do utile, em chave especificamente bucólica, foi aprofundada, em particular, por Cruz e Silva. Para o autor de Sobre o estilo das éclogas, a poesia adquire uma dimensão projectiva, pois não deve imitar servilmente a natureza, mas "[...] discorrer por todos os objectos, que a Natureza lhe oferece naquela espécie do que pretende debuxar, e de todos eles escolher, o que parece mais digno; e, unindo-o na fantasia, formar de todas estas ideias particulares uma ideia universal, a qual lhe sirva de modelo na sua pintura" ${ }^{10}$. A este objectivo de aperfeiçoa-

9 Obras completas, texto fixado, prefácio e notas por António José Saraiva, Lisboa, Sá da Costa, 1982, 2. ${ }^{a}$ ed., vol. 2, p. 106.

10 Obras, vol. 1, p. 254. 
mento estético, associam-se propósitos de ordem formativa, já que as éclogas "[...] nos podem inspirar o amor das virtudes e horror dos vícios que é a maior utilidade que nos pode dar a Poesia"11.

Mas, para além disso, pretendo sublinhar um aspecto que enunciei ao iniciar este trabalho, relativo ao espectro do bucolismo, entre plano poético e desempenho socializante. O lugar que cabe ao bucolismo, na Arcádia Lusitana, como convenção socializante de carácter prescritivo, fica desde logo consignado no primeiro capítulo dos seus estatutos:

Chamar-se-á esta nova Academia - ARCÁDIA - e o lugar das suas conferências o monte Ménalo, bastantemente celebrado das frautas dos Pastores. Os seus alunos se fingirão de Árcades e escolherá cada um um nome e sobrenome de pastor adequado a esta ficção, para por ele ser conhecido e nomeado em todos os exercícios e funções da Arcádia. ${ }^{12}$

Nome da agremiação, local das reuniões e denominação dos seus membros reentram na esfera do pastoril. Desta feita, os parâmetros de comportamento são pautados pelas convenções bucólicas e a academia converte-se, programaticamente, numa representação dramatizada que se desenrola sobre um grande palco, na sociabilidade serena de deliciosas paisagens. É como se fosse um teatro cuidadosamente construído. Serviu-lhe de modelo organizativo, como se sabe, a Accademia dell'Arcadia Romana, fundada em 1690 por um grupo de escritores de entre os quais se contam Giovan Mario Crescimbeni, Vincenzio Leonio, Gian Vincenzo Gravina e Giambattista Felice Zappi.

A Arcádia Lusitana não tem vindo a merecer, em termos gerais, o reconhecimento crítico, entre Teófilo Braga, que

11 Ib., p. 260.

12 Apud Correia Garção, cit., vol. 2, p. 234. 
lamenta o "espírito de futilidade deplorável" que a domina ${ }^{13}$, e Aníbal Pinto de Castro, quando destaca a "secura que a estreiteza normativa do Neoclassicismo não poderia deixar de originar em poesia" ${ }^{14}$. Mas esse distanciamento tem antecedentes bastante mais recuados no tempo, se considerarmos que já Francisco de Pina e Melo, contemporâneo dos Árcades, reagia contra a agremiação.

Não é, contudo, sobre os juízos de valor acerca da sua actividade que me irei deter, mas antes sobre as motivações das perplexidades que têm vindo a ser suscitadas pela rede de contradições identificadas no seu perfil poético-institucional. Refiro-me ao choque entre, por um lado, o carácter inovador do seu programa literário e dos objectivos visados e, por outro lado, o uso de símbolos regressivos ligados a um primitivismo que põe em causa o curso da história. À luz desse ponto de vista, já se considerou que o seu pioneirismo colide com o retrocedimento até uma "[...] idade patriarcal estranha à civilização" "15. Recorde-se, porém, que os sócios da Arcádia mais envolvidos nos trabalhos eram homens que viviam num ambiente urbano, a capital, e muitos deles tinham profissões ligadas ao desenvolvimento citadino. Cruz e Silva e Correia Garção trabalharam na magistratura e em repartições da administração régia, tendo sido, este último, durante um certo período, redactor da Gazeta de Lisboa, dada a sua ligação ao Ministério dos Negócios Estrangeiros e da Guerra. E, contudo, enquanto Árcades, todos eles usaram a máscara pastoril, acatando e fazendo suas convenções próprias da esfera rural.

Ora, adiantando a tese que passarei a expor, tais oposições não são mais do que a herança bucólica na Arcádia Lusitana,

13 História da literatura portuguesa. Os Árcades. 4. ${ }^{\circ}$ volume [1918], Lisboa, IN-CM, 1984, p. 132.

14 "Alguns aspectos da teorização poética no Neoclassicismo português", in Bracara Augusta, vol. 28, n. ${ }^{\circ}$ 65-66 (77-78), pp. 16-17.

15 Teófilo Braga, cit., p. 133. 
com todas as suas implicações ao nível poético e de comportamento, e o seu fulcro é o modo bucólico. A partir da categoria de modo, conforme é definida por Vítor Manuel de Aguiar e Silva, enquanto entidade meta-histórica, também o bucolismo poderá ser definido como modo dotado de particular especificidade no plano semântico-pragmático $^{16}$. Funciona como um modo não disjuntivo. $\mathrm{O}$ signo linguístico adquire uma dupla referencialidade, na medida em que, à relação não motivada entre significante e significado que está ligada a um sistema linguístico institucionalizado, nos termos de Saussure, uma outra se vem acrescentar, de ordem simbólica. A personagem é o pastor, o pescador ou o ceifeiro e, ao mesmo tempo, representa uma determinada pessoa. Significado institucionalizado e significado simbólico não chocam entre si, nem tão pouco se anulam: coexistem. O Sincero da Arcadia não é aut pastor, aut desdobramento simbólico de Sannazaro, é um $e$ outro: $e$ pastor, e alter ego de Sannazaro. A decodificação do texto bucólico requer, pois, o estabelecimento de um pacto específico com o leitor, um pacto bucólico. Só está ao alcance de quem possuir a chave do enigma, no âmbito de convenções restritivas.

É desse teor o pacto que os estatutos da Arcádia Lusitana instituem, logo desde o seu primeiro capítulo. A academia chama-se Arcádia, como a mítica terra de pastores que Virgílio converteu em pátria do canto pastoril por excelência. Na sétima écloga, dá a Coridon e Tirse origens arcádicas e dotes canoros de excepção: "ambo florentes aetatibus, Arcades ambo,/et cantare pares et respondere parati"17. Por sua vez, a eleição do Ménalo como sede de reunião remete para um outro conhecido passo de Virgílio, também ligado ao

16 Tive oportunidade de definir o bucolismo como modo, de estudar o percurso histórico que vai de Dante a Sannazaro e de analisar a estrutura da Arcadia, em A "Arcadia" de Sannazaro e o bucolismo, Coimbra, FLUC, 1995.

17 Buc. 7.4-5. 
canto, às possibilidades de remissão que oferece, e ao orfismo: "pinifer illum etiam sola sub ripe iacentem/Maenalus et gelidi fleuerunt saxa Lycaei"18. Estes lugares foram consagrados, para os séculos vindouros, pela obra-prima de Sannazaro, a Arcadia, logo a partir do seu título e da prosa introdutiva, na qual são celebrados os pinheiros do Ménalo. Como tal, os Árcades, "com nome e sobrenome de pastor adequado", conforme estabelecem os estatutos, são aquelas figuras que, desde Teócrito até aos nossos dias, se cobrem das vestes pastoris sem deixarem de representar entidades históricas, fruto de uma adequada simbologia.

Por conseguinte, a leitura da sociabilidade arcádica em chave bucólica é indissociável da tradição literária do classicismo, entendida, com Amedeo Quondam, no seu sentido etno-antropológico. A pedra miliária da recuperação do género é o Dante do período que medeia entre 1320 e 1321, ano da sua morte. Dante restaura o bucolismo num contexto dialógico que tem por veículo a epístola métrica em latim, através da correspondência em hexâmetros que troca com Giovanni del Virgilio. Num quadro literário tão rico como complexo e sibilino, é problemático determinar onde começa a mistificação e acaba a idealização de um diálogo caracterizado por uma subtil ironia.

Giovanni era um mestre de latim muito sabedor, como tantos outros da Itália do seu tempo, que ensinou na Universidade de Bolonha, mas com a particularidade de ser tão diligente e perseverante leitor e admirador de Virgílio que lhe foi associado o nome do autor da Eneida. Não se coibiu de dirigir ao autor da Commedia (cuja crescente fama chegava, transversalmente, a todos os estratos de público) uma epístola na qual lamentava que uma obra de tanta erudição tivesse sido escrita em vulgar e pudesse atrair a atenção do povoléu, dando pérolas a porcos: "Nec margaritas profliga 
prodigus apris"19. Mais do que isso, dá alguns conselhos práticos a Dante que entende lhe poderão ser muito úteis para obter a coroa de louros. Preconiza, então, que escreva um poema em latim, de tema histórico ou épico, já que um tema elevado requer uma linguagem elevada. Bem o sabia o aplicado leitor de Virgílio, com o exemplo da Eneida na sua mente. Dante responde com primorosa finura ao advogado do gravis stilus, usando o mais humilde dos estilos. De acordo com a chamada roda de Virgílio, muito divulgada durante a Idade Média, o estilo considerado mais elevado, que era o épico, tinha o seu contraponto no estilo mais simples, o bucólico. O autor da Commedia cobre-se de vestes pastoris, coloca o seu destinatário no Ménalo, instala-se num pacato cenário natural e assevera que as matérias humildes o levarão à glória. Na sua amplitude, o canto dos corpos do universo, dos habitantes das alturas e dos reinos inferiores dar-lhe-á, seguramente, a alegria de cingir a hera e o louro: "[...] Cum mundi circumflua corpora cantu/astricoleque meo, velut infera regna, patebunt,/devincere caput hedera lauroque iuvabit". Mais do que isso, promete a Giovanni del Virgilio dez éclogas, "decem missurus vascula" ${ }^{20}$. Na sua concisão, os hexâmetros de Dante condensam o programa de séculos e séculos de bucolismo.

Ao responder-lhe, Giovanni embrenha-se por convenções pastoris saturadas de Virgílio, mas, preocupado em conferir realidade à ficção, situa o seu interlocutor (que lhe escrevia de Ravena) nas margens do Pó. Dante não perde essa oportunidade para levar por diante o seu magistério, fazendo-lhe ver que ele desconhece que a colina onde ambos se

19 Os quatro textos desta correspondência são editados, com tradução italiana, em Dante Alighieri, Opere minori, vol. 3, t. 2, Epistole. Ecloge. Questio de aqua et terra, a cura di Arsenio Frugoni, Giorgio Brugnoli, Enzo Cecchini, Francesco Mazzoni, Milano, Napoli, Riccardo Ricciardi, 1996, pp. 652-689, cit. 1.21, p. 656.

${ }^{20}$ 2.49-51, p. 666; 2.64, p. 668, respectivamente. 
encontram é a Trinácria, o mais fértil dos montes da Sicília: "[...] quo non fecundius alter" 21 . Da mesma feita, dilui as referências de voz, o simbolismo das personagens e o papel das instâncias mediadoras. Mais uma lição de poética bucólica: ou se está dentro ou se está fora do país dos pastores. Quem nele quer entrar tem de aceitar, com toda a humildade, as suas regras e as convenções prescritivas que o regem. A poesia adquire, assim, uma dimensão abrangente, que se sobrepõe a todas as circunstâncias. Da mesma feita, carrega também consigo decisivas resignações. À cabeça de todas elas, a renúncia ao canto épico, aquela renúncia primacial na ideação da Commedia, depois reiterada perante o advogado do gravis stilus e convertida em oportunidade bucólica. Como Dante ensinou a Giovanni del Virgilio, no Ménalo ou na Trinácria, o canto dos pastores não assume a história. Michele Feo definiu-o como método, o método do não empenhamento ${ }^{22}$. Nem a conversão, nem a regeneração reentram nos seus objectivos. Esse universo de ficção existe para quem está dentro dele, é o lugar do retiro, como diz Renato Poggioli²3. A renúncia de Dante ressoa, pois, na renúncia de todos os cultores do bucolismo, confinados a um mundo que não assume a história e que desconhece heróis.

Face a este conjunto de dados, poderemos compreender mais claramente como o bucolismo é o elemento resolutivo da rede de contradições que têm vindo a ser apontadas na Arcádia Lusitana, afinal aparentes. A capa bucólica é, no fundo, um modo e um método de defender um programa de renovação cultural avançado, em oposição ao Barroco, mas sob forma camuflada. Acresce a essa circunstância o facto

21 4.71, p. 686

22 "Tradizione latina", in Letteratura italiana, direzione Alberto Asor Rosa, vol. 5, Le questioni, Torino, Einaudi, 1986 [e reimpr.], pp. 311-378.

23 "Pastorals of Innocence and Happiness" [1957], The Oaten Flute. Essays on Pastoral Poetry and the Pastoral Ideal, Cambridge Massachusetts, Harvard University Press, 1975, pp. 1-16. 
de a agremiação nunca ter obtido o ambicionado reconhecimento institucional pela parte do poder. Carvalho e Melo, por entre as ruínas do terramoto, dava passos decisivos para a sua ascensão, sem se comprometer, porém, com o patrocínio oficial da academia, enquanto os gostos do grande público continuavam a privilegiar a exuberância barroca. Teófilo notou que a Arcádia não recebeu o favor régio, apesar da sua propensão encomiástica ${ }^{24}$. António José Saraiva associou-a à afirmação burguesa, considerando a sua vertente comemorativa como de circunstância ${ }^{25}$. Mais recentemente, Ivan Teixeira associou-a ao programa governativo de Carvalho e Melo $^{26}$, dirigindo a sua atenção, contudo, para um núcleo específico de textos celebrativos. Mas a minha leitura passará a incidir sobre uma outra vertente do seu funcionamento, enquanto instituição que fundamenta, através do modo bucólico, aquela Trinácria de Dante.

As novas formulações geradas no seio da Arcádia Lusitana visam desígnios onde passado e futuro se intersectam: no presente. São os pólos consagrados pelo ensaio que Auden dedicou ao bucolismo, quando o coloca entre Idade do Ouro e Utopia ${ }^{27}$. Do passado, os Árcades recuperam a lição de limpidez clássica e com ela o exemplo dos Antigos, bem como a lição dos escritores portugueses do século XVI e dos grandes autores do Renascimento europeu. Em direcção ao futuro, lançam um programa que tem por metas "a instrução e o verdadeiro gosto da Poesia", conforme se lê no quarto capítulo dos seus estatutos. Esse vaivém entre passado

24 Razão pela qual, com um laivo de indisfarçável ironia, a considera "simpática” (Teófilo Braga, A Arcádia Lusitana. Garção, Quita, Figueiredo, Dinis, Porto, Chardron, Sucessores Lello \& Irmão, 1899, p. 209).

25 "Introdução", apud António Dinis da Cruz e Silva, vol. 1 e 2.

26 Mecenato pombalino e poesia neoclássica, São Paulo, Edusp, 1999.

27 “Dingley Dell and the Fleet" [1948], The Dyer's Hand and Other Essays, New York, Random House, 1990, pp. 407-428. Este ensaio é prototípico fruto do clima que se vivia no rescaldo da Segunda Guerra. 
e futuro processa-se selectivamente. O meio braço que pega num podão com a epígrafe, inutilia truncat, escolhido como empresa da agremiação, de acordo com o segundo capítulo dos estatutos, carrega consigo a dupla referencialidade do signo bucólico: instrumento agrícola e símbolo dos propósitos renovadores dos Árcades. No seu alcance projectual, virado para o futuro, a Arcádia Lusitana faz-se herdeira da Utopia bucólica. Da Idade do Ouro, de um mítico passado glorioso, herda o sentido idealizante. É essa a sua ficção: "os seus alunos se fingirão de Árcades, e escolherá cada um um nome e sobrenome de pastor adequado a esta fiç̧ão".

$\mathrm{Na}$ verdade, a máscara bucólica não choca com o ambiente urbano, desdobra-o. O pastor-Árcade é um poeta e a Arcádia é a cidade onde vive. O cenário que enquadra a sua actividade é o da reconstrução urbana da Lisboa pós-Terramoto, caracterizado por uma intensa sociabilidade e até por um certo cosmopolitismo. As reuniões que se realizavam na Fonte Santa, em casa de Correia Garção, eram frequentadas por vários dos seus amigos, por alguns sócios da Arcádia e também por estrangeiros estantes em Portugal, como o arquitecto húngaro Carlos Mardel, o coronel Mac Bean ou os oficiais austríacos Weinholtz. As circunstâncias da reconstrução, depois do terramoto, tornavam absolutamente necessária a aceleração dos contactos com outros países. Através desse sistema de circulação, mais facilmente chegavam também a Portugal as ideias e os livros. Ora, os escritos dos Árcades, em particular os de índole teórica, revelam um conhecimento de obras e autores ligados ao Neoclassicismo que só em Verney encontravam um precedente à altura. Aliás, se a fundação da Arcádia Lusitana desdobra a da Accademia dell'Arcadia Romana, na introdução aos seus estatutos são referidas agremiações que a envolvem um contexto europeu muito vasto: a Academia Florentina, a Academia da Crusca, a Academia das Inscrições e Belas Letras, a Academia del Cimento, a Régia Sociedade de Londres, a Academia Real das Ciências 
de Paris e a Academia de San Fernando de Madrid. Nesse sentido, o Ménalo desta Arcádia fica muito distante daquela Corte na aldeia, que teve por autor o desditoso poeta que morreu tragicamente, afogado nas águas do Tejo, quando fazia uma viagem de Lisboa para Santarém.

A máscara bucólica simboliza a própria possibilidade da poesia, no que tem de imaginação e arte, seja o assunto simples ou elevado:

Talvez se vê um Poeta obrigado a tratar assuntos mais elevados; mas para isso lá está Sileno, se intenta cantar a origem do Mundo; ou Proteu, se quer descrever a Guerra dos Gigantes, e os trabalhos de Hércules; e se a morte de Júlio César, ou de D. António de Noronha é o assunto de seus Versos, não falta um Pastor Dáfnis, ou Tionio, com que aquelas personagens se encubram. Não se pode encarecer o grande cuidado, e diligência, que requerem semelhantes matérias para serem tratadas numa Écloga com a devida decência, e sem se faltar ao carácter, e propriedade desta composição. Devem ser cobertas duma fina alegoria, que como o véu, com que Camões cobriu o delicado corpo da formosa Vénus, não há-de esconder aos olhos dos que o contemplarem o objecto, com que ele se encobre. ${ }^{28}$

O confronto entre o realismo do quotidiano e o artificio não esconde o objecto, vela-o através de um modo literário, o bucolismo. Esse programa de renovação passa também pela possibilidade de alcançar uma visão mais articulada do mundo $^{29}$. Daí decorrem duas questões, que considero essen-

28 António Dinis da Cruz e Silva, cit., vol. 1, p. 241.

29 Esta situação mantém algumas semelhanças com a cornice do Decameron, em cuja composição aflora o modo bucólico. O retiro no campo do grupo de jovens que abandona uma cidade devastada pela peste e adopta pseudónimos e convenções de circunstância oferece-se também enquanto oportunidade para um olhar mais penetrante e atento sobre a vida urbana, com os seus vícios e as suas virtudes. 
ciais, quanto às ressonâncias do programa literário e da eficácia, no terreno, da actividade dos Árcades.

A impregnação de atitudes e comportamentos pela máscara pastoril é uma escolha que tem o seu preço. As suas consequências remontam à rejeição do repto que Giovanni del Virgilio lançara a Dante e à sua redescoberta: a opção pastoril carrega consigo a renúncia ao épico, à heroicidade e à história. Na verdade, os ecos do magistério da Arcádia Lusitana não foram imediatos. Os abundantes repositórios da poesia barroca, a Fénix renascida (1716-1728, com um sucesso tal que em 1746 saiu nova edição) e, em plenos anos de 1761-1762, os Eccos que o Clarim da Fama dá: Postilhão de Apollo montado no Pegazo, girando o Universo para divulgar ao Orbe Literario as Peregrinas Flores da Poezia Portugueza com que vistosamente se esmaltão os Jardins das Musas do Parnazo, continuavam a deleitar o grande público. Foram décadas e décadas a fio de entusiástico convívio com aqueles jogos rebuscados que o podão dos Árcades colocava sob a mira do inutilia truncat. Qualquer programa decididamente renovador, no Portugal daqueles anos, só o poderia efectivamente ser em função do utile. Bem o sabiam os Árcades, pela centralidade que conferiram a esse propósito. Mas foi enquanto Árcades que o puseram em acção, impregnados pelas convenções bucólicas que regiam toda a sua actividade, do podão ao nome pastoril, do plano poético ao do desempenho socializante. $\mathrm{O}$ bucolismo não assume a história, não é o modo do empenhamento, não é o método da conversão nem da regeneração, mas do retiro. O Árcade vive no seu próprio jardim, o qual é muito parecido, nota Poggioli, com o de Candide: que não é um jardim público.

Tange chelim, tantos hominum compesce labores.

$\mathrm{Ni}$ canis hec alios a te pendendo poeta, omnibus ut solus dicas, indicta manebunt. ${ }^{30}$ 
Giovanni del Virgilio bem tinha exortado Dante a que, com a sua cítara, abarcasse os grandiosos trabalhos dos homens, pois se não fosse ele, poeta, a cantá-los, um só a falar para todos, esses feitos ficariam por contar. "Omnibus ut solus dicat": um só que eleva a sua voz para todos e por todos, de acordo com o estatuto do poema épico que consagra a gesta e a história de um inteiro povo a uma só voz. A este desafio, Dante sobrepôs o retiro arcádico. Ou se está dentro ou se está fora do país dos pastores. Quem nele entra, tem de aceitar as suas regras, com a humildade própria do seu estilo e do seu estatuto modal. Ao cobrirem-se das insígnias pastoris, os sócios da Arcádia Lusitana renunciaram à heroicidade ${ }^{31}$.

Mas, e passando à segunda questão, é essa mesma linha demarcadora que, ao instituir quem está dentro dela, relativamente a quem está fora, faz da Arcádia um dos fundamentais marcos miliários do percurso da literatura portuguesa do século XVIII. Na Trinácria ou no Ménalo lusitano, o universo da poesia é superlativo, "[...] quo non fecundius alter" 32 . A linha separadora entre quem está dentro ou fora dele assinala o espaço da poesia como institutio que consagra o literário, no seu valor formativo e social. Desta feita, os sócios da Arcádia Lusitana fizeram-se membros, de pleno direito, de uma outra arcádia, aquela arcádia para onde o velho Dante já tinha conduzido Giovanni del Virgilio, o domínio da poesia.

31 Já Helena Buescu observou que, na simplicidade resultante da articulação entre quotidiano e coloquialidade através da ironia, reside uma atitude anti-heróica ("De trajes antigos e homens modernos, ou: Correia Garção e André Chénier”, A lua, a literatura e o mundo, Lisboa, Cosmos, 1995, pp. 181-195).

32 4.71, p. 686. 